$$
\text { CONF-9705122--1 }
$$

Note: This is a preprint of a paper submitted for publication. Contents of this paper should not be quoted or referred to without permission of the author(s).

To be presented at American Society for Artificial Internal Organs (ASAIO)

43rd Annual Conference, Atlanta, Georgia, May 1-3, 1997 and published in Proceedings

\title{
THIN-FILM RECHARGEABLE LITHIUM BATTERIES FOR IMPLANTABLE DEVICES
}

J. B. Bates and N. J. Dudney Solid State Division, Oak Ridge National Laboratory

Oak Ridge, TN 37831-6030

The submitted manuscript has been authored by a contractor of the U.S. Government under contract No DE-AC05-960R22464. Accordingly, the U.S. Government retains nonexclusive, royalty-free license to publish or nonexclusive, the contribution, or allow others to do so, for U.S. contribution, or allow

\section{Prepared by \\ SOLID STATE DIVISION \\ OAK RIDGE NATIONAL LABORATORY \\ Managed by \\ LOCKHEED MARTIN ENERGY RESEARCH CORP. under \\ Contract No. DE-AC05-96OR22464 with the \\ U.S. DEPARTMENT OF ENERGY \\ Oak Ridge, Tennessee}

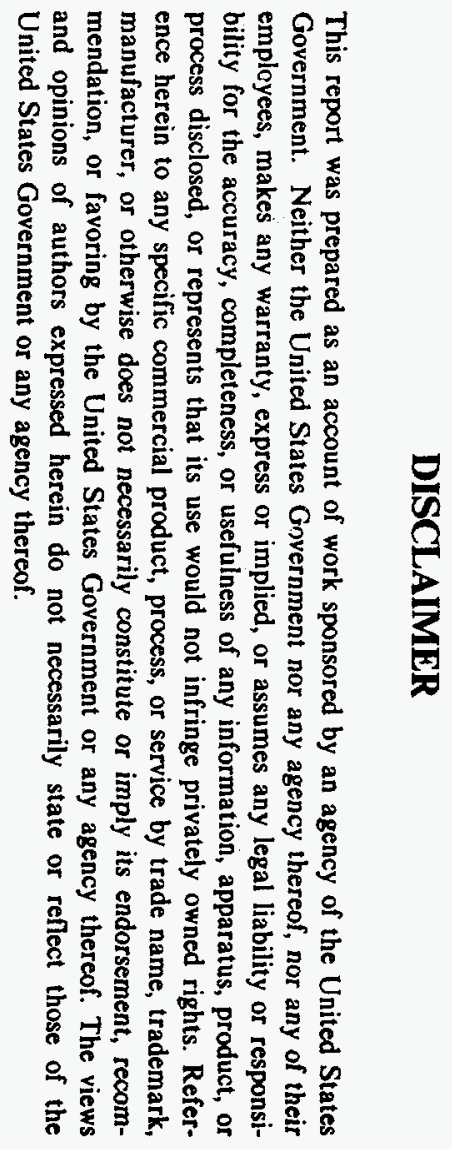

May 1997 


\section{DISCLAIMIER}

Portions of this document may be illegible in electronic image products. Images are produced from the best available original document. 
THIN-FILM RECHARGEABLE LITHIUM BATTERIES FOR IMPLANTABLE DEVICES

John B. Bates, Ph.D. and Nancy J. Dudney, Ph.D.

Solid State Division, Oak Ridge National Laboratory

Oak Ridge, Tennessee 37831-6030

Running title: THIN-FILM RECHARGEABLE LITHIUM BATTERIES

Send reprints to:

J. B. Bates, Oak Ridge National Laboratory

MS 6030,

Oak Ridge, TN, 37830-6030 


\begin{abstract}
Thin films of $\mathrm{LiCoO}_{2}$ have been synthesized in which the strongest $\mathrm{x}$-ray reflection is either weak or missing, indicating a high degree of preferred orientation. Thin-film solid state batteries with these textured cathode films can deliver practical capacities at high current densities. For example, for one of the cells $70 \%$ of the maximum capacity between $4.2 \mathrm{~V}$ and $3 \mathrm{~V}(\sim 0.2$ $\mathrm{mAh} / \mathrm{cm}^{2}$ ) was delivered at a current of $2 \mathrm{~mA} / \mathrm{cm}^{2}$. When cycled at rates of $0.1 \mathrm{~mA} / \mathrm{cm}^{2}$, the capacity loss was $0.001 \% / c y c l e$ or less. The reliability and performance of $\mathrm{Li}-\mathrm{LiCoO} 2$ thin-film batteries make them attractive for application in implantable devices such as neural stimulators, pacemakers, and defibrillators.
\end{abstract}

\title{
Introduction
}

Solid state rechargeable lithium batteries which are less than $15 \mu \mathrm{m}$ (micrometers) thick have been developed at the Oak Ridge National Laboratory. These batteries have high energy and power densities, can be cycled thousands of times, and they can be fabricated in arbitrary shapes and to any required size to meet the requirements of a specific application. When fabricated directly onto multichip packages, the batteries can save 100-1000 times the volume required by conventional lithium coin cells.

A schematic cross section of a thin-film battery is shown in Fig. 1. The active battery components are a lithium intercalation cathode, e.g. $\mathrm{V}_{2} \mathrm{O}_{5}, \mathrm{LiMn}_{2} \mathrm{O}_{4}$ or $\mathrm{LiCoO}_{2}$, and a lithium metal anode which are separated by a lithium phosphorus oxynitride electrolyte (1). Graphs of voltage vs. discharge capacity for thin film cells with different types of crystalline and amorphous cathodes are shown in Fig. 2. Among the materials we have investigated, batteries with crystalline $\mathrm{LiCoO}_{2}$ cathodes have the highest energy and power densities (2), making them attractive as compact rechargeable power sources for application in a variety electronic devices including neural stimulators, pacemakers, and defibrillators.

Crystalline $\mathrm{LiCoO}_{2}$ has a layered structure in which lithium and cobalt ions are located in alternate planes that are separated by close-packed oxygen planes (3). In an earlier work (2), we 
reported that thin-film rechargeable lithium batteries with crystalline $\mathrm{LiCoO}_{2}$ cathodes could deliver of the order of $25 \mu \mathrm{Ah}$ per $\mathrm{cm}^{2}$ of charge at rates up to $1000 \mu \mathrm{A} / \mathrm{cm}^{2}$ and could be cycled thousands of times with small capacity losses. The x-ray diffraction patterns of these films typically displayed a strong (003) reflection and weaker (101) and (104) reflections. Recently, we observed that diffraction patterns of annealed $\mathrm{LiCoO}_{2}$ films that had been grown in different vacuum chambers using different $\mathrm{LiCoO}_{2}$ targets displayed either a very weak or absent (003) reflection and a strong (104) or (101) reflection, indicating a high degree of preferred orientation or texturing. Batteries with these textured cathodes have significantly higher power and energy densities compared to those described earlier (2). In this paper, we discuss the effects of preferred orientation on the performance of thin-film lithium batteries.

\section{Experimental Procedures}

The $\mathrm{LiCoO}_{2}$ films, 1 to $3 \mu \mathrm{m}$ thick, were deposited over Pt current collectors on alumina substrates by rf magnetron sputtering of 2" diameter $\mathrm{LiCoO}_{2}$ targets (2). The process gas was a $3 / 2$ mixture of $\mathrm{Ar} / \mathrm{O}_{2}$, the total pressure was $20 \mathrm{mTorr}$, and the target-to-substrate distance was $5 \mathrm{~cm}$. Depositions were made in two vacuum chambers with different volumes and orientation of the sputter guns. Targets were prepared by cold pressing and sintering $\left(1100^{\circ} \mathrm{C}\right.$ in air) powders of $\mathrm{LiCoO}_{2}$ obtained from Cerac (>99.5\%) and Alfa Aesar (>98\%). After deposition, the films were recrystallized by annealing in $\mathrm{O}_{2}$ at $700^{\circ} \mathrm{C}$ for $2 \mathrm{~h} . \quad \mathrm{X}$-ray diffraction measurements were made on the commercial powders and the annealed films over the 2-theta range from 10 to $70^{\circ}$. Thin-film cells with the annealed cathodes were fabricated using the deposition methods described previously (1), and their performance was evaluated by constant current cycling using a battery test system with high impedance channels.

Results and Discussion

Structure of the $\mathrm{LiCoO}_{2}$ films

The regions near the (003), (101), and (104) reflections of three representative $\mathrm{LiCoO}_{2}$ films are shown in Fig. 3. The integrated intensities of the diffraction peaks were scaled to 100 for the 
strongest reflection from each film, and their values are listed in Table I. The relative intensities observed with the powdered sample of $\mathrm{LiCoO}_{2}$ (Table I) are in good agreement with the results reported previously for powdered samples of the high temperature form of $\mathrm{LiCoO}_{2}(4)$ and also with the calculated diffraction pattern based on the cell parameters and atomic positions reported by Orman and Wiseman (3). The latter are the relative intensities expected for a random orientation of crystalline $\mathrm{LiCoO}_{2}$ grains.

Scanning electron micrographs of fracture cross sections reveal that the films consist of columns of $\mathrm{LiCoO}_{2}$ grains normal to the plane of the substrate. Provided a reflection is allowed by the crystal symmetry, diffraction can occur from only those crystal planes that are parallel to the surface of the substrate. The relative intensities of the three reflections shown in Fig. 3 are determined by their respective intrinsic intensities and by the fraction of the grains which are oriented such that their (003), (101), or (104) planes are parallel to the plane of the substrate. Comparing the relative intensities Table I with the values for the randomly oriented powdered sample, it is apparent that the three representative films exhibited significant texturing with different preferred orientation of the $\mathrm{LiCoO}_{2}$ grains. The relative percentages of grains with one of the three preferred orientations were calculated by dividing the intensity observed for each of the three reflections of the films by the intensity of the corresponding reflections of the powdered sample and then normalizing the values for each film to $100 \%$. The results are given in Table II. For example, dividing the intensities of film $\mathrm{A}$ by the corresponding powder intensities gives 1.0, 2.0 , and 0.46 , respectively, as the relative number of grains with their (003), (101), and (104) planes parallel to the substrate compared to the random powder distribution. Normalizing to $100 \%$ gives the percentages of the grains with each of the three particular orientations for film $\mathrm{A}$ (first row of Table II).

At the present time we do not understand the cause of the texturing of the $\mathrm{LiCoO}_{2}$ films nor the origin of the differences in textures of films grown in different vacuum chambers and with different $\mathrm{LiCoO}_{2}$ targets. It is known from other studies (5) that preferred orientation is due to the tendency to minimize the larger of the surface energy or the strain energy of a film. Both of 
these energies differ from one crystallographic plane to another, and their relative values for the different planes generally do not have the same order. So if surface energy is dominant, a film will grow with one preferred orientation whereas if strain energy is dominant a film will grow with a different orientation. Surface energy is determined by the details of the crystal structure (coordination number and bond strengths) while the strain energy is determined by the stress in the film and the elastic properties of the material (5). The latter of course also depend on the details of the crystal structure. In general, the thinner the film the more likely that surface energy is dominant, while as the film becomes thicker the strain energy is larger (5). We speculate that for the relatively thicker films ( 1 to $3 \mu \mathrm{m}$ ) strain energy plays the more important role. From preliminary electron diffraction measurements on individual grains in as-deposited films (6), it appears that texturing is initiated during film growth.

\section{Battery performance}

Differences in the texturing of $\mathrm{LiCoO}_{2}$ films result in differences in the resistance to lithium ion transport. From the schematic drawing in Fig. $1, \mathrm{Li}^{+}$ions move perpendicular to the plane of the cathode films during charge and discharge. Since in the $\mathrm{LiCoO}_{2}$ structure the $\mathrm{Li}^{+}$occupy alternate layers which are perpendicular to the c-axis, we expect a higher resistivity for films with a larger percentage of (003) oriented grains since $\mathrm{Li}^{+}$diffusion perpendicular to the (003) planes will be much slower than diffusion within (parallel) to these planes. The angles between the (003) and the (101) and (104) planes are $45^{\circ}$ and $14^{\circ}$, respectively. Therefore we expect $\mathrm{Li}^{+}$ diffusion perpendicular to either of these planes is faster than in a direction perpendicular to the (003) planes.

Constant current discharge curves for a cell with a $2 \mu \mathrm{m}$ thick film are shown in Fig. 4. The downward shift of the discharge curves with increasing current density is due to the internal resistance of the cell. Comparing similar curves for cells with each of the three types of cathodes of Table II, we find that batteries with B or C type cathodes have resistivities (resistance/cathode thickness) that are lower by as much as three times the resistivity of batteries with type A cathodes. Moreover, batteries with type B cathodes have resistivities lower by as much as $30 \%$ 
compared to batteries with type $\mathrm{C}$ cathodes. Lower resistivities allows cells to be discharged at higher rates while delivering most of the available charge between $4.2 \mathrm{~V}$ and $3.0 \mathrm{~V}$. This is illustrated by the graphs in Fig. 5 of the discharge capacity vs. current density obtained from the data in Fig. 4 and similar data for a cell with a $1.3 \mu \mathrm{m}$ thick cathode. Both the $2 \mu \mathrm{m}$ and $1.3 \mu \mathrm{m}$ thick cathodes were type B. Even with the thicker cathode, the discharge capacity is above $50 \%$ of maximum at a current density of $3 \mathrm{~mA} / \mathrm{cm}^{2}$. For comparison, data available over a limited range for a battery with a type A cathode also is shown. The much more rapid decrease in capacity with current is caused by the three times higher resistivity of the type A cathode.

Thin-film batteries with type B or C cathodes are also capable of delivering high pulse currents. This is illustrated in Fig. 6. The application in this case called for $2.3 \mathrm{~mA} / \mathrm{cm}^{2}$ pulses of $15 \mathrm{~s}$ duration separated by a rest period of $2 \mathrm{~s}$. A minimum of five pulses was required on each cycle, i.e. before the battery is recharged. As illustrated, this particular cell could deliver eight of the required pulses before recharge.

The secondary performance of batteries with type B or C cathodes appears to be as good as those with type A cathodes (2) as illustrated in Fig. 7. For both cells, the capacity loss was about $0.001 \% / c y c l e$ at discharge rates of $0.1 \mathrm{~mA} / \mathrm{cm}^{2}$. This means, for example, that $95 \%$ of the original capacity remains after 5000 cycles.

Most of our battery tests have been conducted at $25^{\circ} \mathrm{C}$, but we have observed the same performance and reliability at $37^{\circ} \mathrm{C}$. This suggests possibilities for application in several types of implantable devices such as neural stimulators, pacemakers, and defibrillators where reliable batteries of the smallest possible size are desirable.

\section{Conclusions}

Thin films of $\mathrm{LiCoO}_{2}$ deposited by rf magnetron sputtering and annealed at $700^{\circ} \mathrm{C}$ in $\mathrm{O}_{2}$ exhibit three types of texturing with a varying distribution of grains having their (003), (101), and (104) planes parallel to the substrate. Thin-film batteries with type B or C cathodes have significantly higher power and energy densities compared to cells with type A cathodes. The type 
of preferred orientation exhibited by the cathode films depends on the kind of $\mathrm{LiCoO}_{2}$ target used and on the chamber in which the films were grown. We speculate that either the surface or stress energy is the leading factor in determining the type of texturing, and we expect that their relative importance depends on film thickness and on subtle differences in deposition parameters such as substrate bias, temperature, and flux of reflected neutral atoms.

\section{References}

1. Bates JB, Dudney NJ, Lubben DC, Gruzalski GR, Kwak BS, Yu X, and Zuhr RA: Thin-film rechargeable lithium batteries. J. Power Sources 54: 58-62, 1995.

2. Wang B, Bates JB, Hart FX, Sales BC, Zuhr RA, and Robertson JD: Characterization of thinfilm rechargeable lithium batteries with lithium cobalt oxide cathodes. J. Electrochem. Soc 143: 3203-3213, 1996.

3. Orman $\mathrm{HJ}$ and Wiseman, $\mathrm{PJ}$ : Cobalt(III) lithium oxide, $\mathrm{CoLiO}_{2}$ : structure refinement by powder neutron diffraction. Acta Cryst. C40: 12-14, 1984.

4. JCPDS card 16-0127 based on the data of Johnston WD, Heikes RR, Sestrich D: The preparation, crystallography, and magnetic properties of the $\mathrm{Li}_{\mathrm{x}} \mathrm{Co}_{(1-\mathrm{x})} \mathrm{O}$ system. J. Phys. Chem. Solids 7: 1-13, 1958.

5. Pelleg J, Zevin LZ, Lungo S, and Croitoru N: Reactive-sputter-deposited TiN films on glass substrates. Thin Solid Films: 117-128, 1991.

6. Hackney S: Private communication.

\section{Acknowledgements}

The authors thank Mr. Chris Luck and Mr. Ivan Dunbar for their help in fabricating the thin-film batteries. This research was supported by The Department of Energy's Division of Materials Sciences, Division of Chemical Science, Office of Energy Research Technology Transfer Program, and Office of Transportation Technologies under contract No. DE-AC0596OR22464 with Lockheed Martin Energy Research Corp. 
Table I. Relative integrated peak areas of (003), (101), and (104) reflections of $\mathrm{LiCoO}_{2}$ thin films

\begin{tabular}{ccrr}
\multicolumn{4}{c}{ Intensity } \\
\hline Film & $(003)$ & $(101)$ & $(104)$ \\
\hline A & 100 & 72 & 29 \\
B & 13 & 100 & 46 \\
C & -- & 15 & 100 \\
Powder & 100 & 30 & 63 \\
\hline
\end{tabular}

No entry (--) indicates a very weak or missing reflection. 
Table II. Relative percentage of grains with either their (003), (101), or (104) planes parallel to the substrate

Percentage

\begin{tabular}{cccc}
\hline Film & $(003)$ & $(101)$ & $(104)$ \\
\hline A & 26 & 62 & 12 \\
B & 3 & 73 & 24 \\
C & - & 24 & 76 \\
\hline
\end{tabular}




\section{Figure Legends}

Fig. 1. Schematic cross section of a thin-film battery.

Fig. 2. Low current discharge curves of thin-film lithium batteries with different crystalline and amorphous cathodes.

Fig. 3. X-ray diffraction from $\mathrm{LiCoO}_{2}$ representative films in the region of the (003), (101), and (104) reflections. Peaks not identified are due to the alumina subsrate and Pt current collector.

Fig. 4. Discharge curves at different current densities for a $\mathrm{Li}-\mathrm{LiCoO}_{2}$ cell with a type B cathode, $1 \mathrm{~cm}^{2} \times 1.3 \mu \mathrm{m}$ thick.

Fig. 5. Discharge capacity per unit of active area vs. current density for two $\mathrm{Li}-\mathrm{LiCoO}_{2}$ cells with type B cathodes (solid squares) of different thicknesses and a cell with a type A cathode (open squares).

Fig. 6. Pulse testing of a $\mathrm{Li}-\mathrm{LiCoO}_{2}$ cell with a $2 \mu \mathrm{m}$ thick type $\mathrm{B}$ cathode. The current pulses were $2.3 \mathrm{~mA} / \mathrm{cm}^{2}$ of $15 \mathrm{~s}$ duration followed by a $2 \mathrm{~s}$ rest.

Fig. 7. Cycle data for thin-film $\mathrm{Li}-\mathrm{LiCoO}_{2}$ batteries with type $\mathrm{A}$ and type $\mathrm{C}$ cathodes. The latest 610 cycles for the latter are shown. 


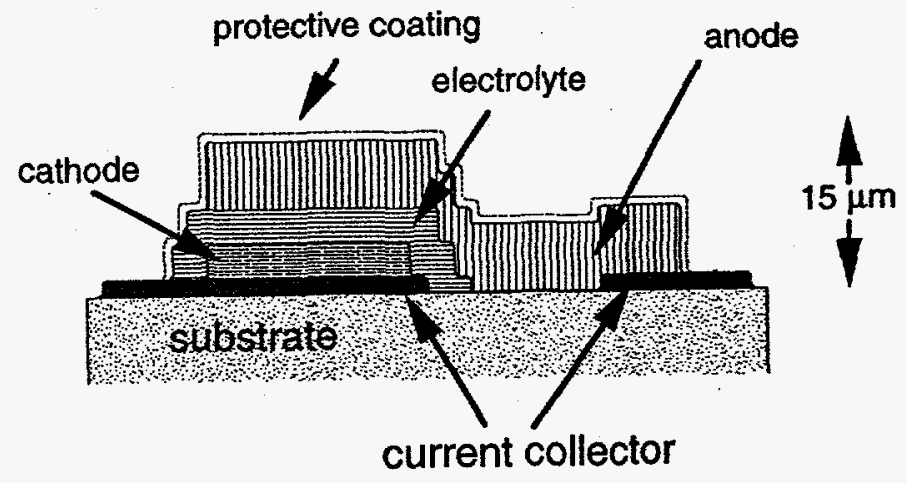




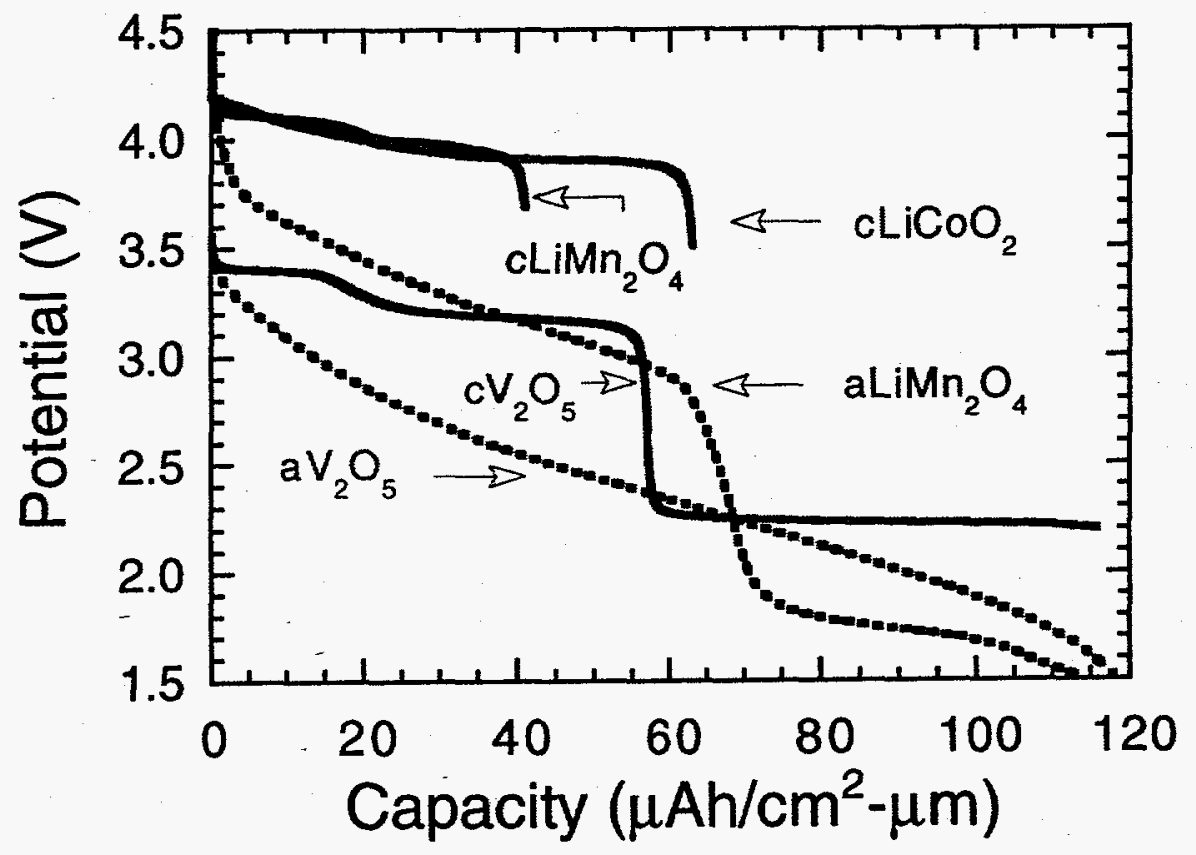




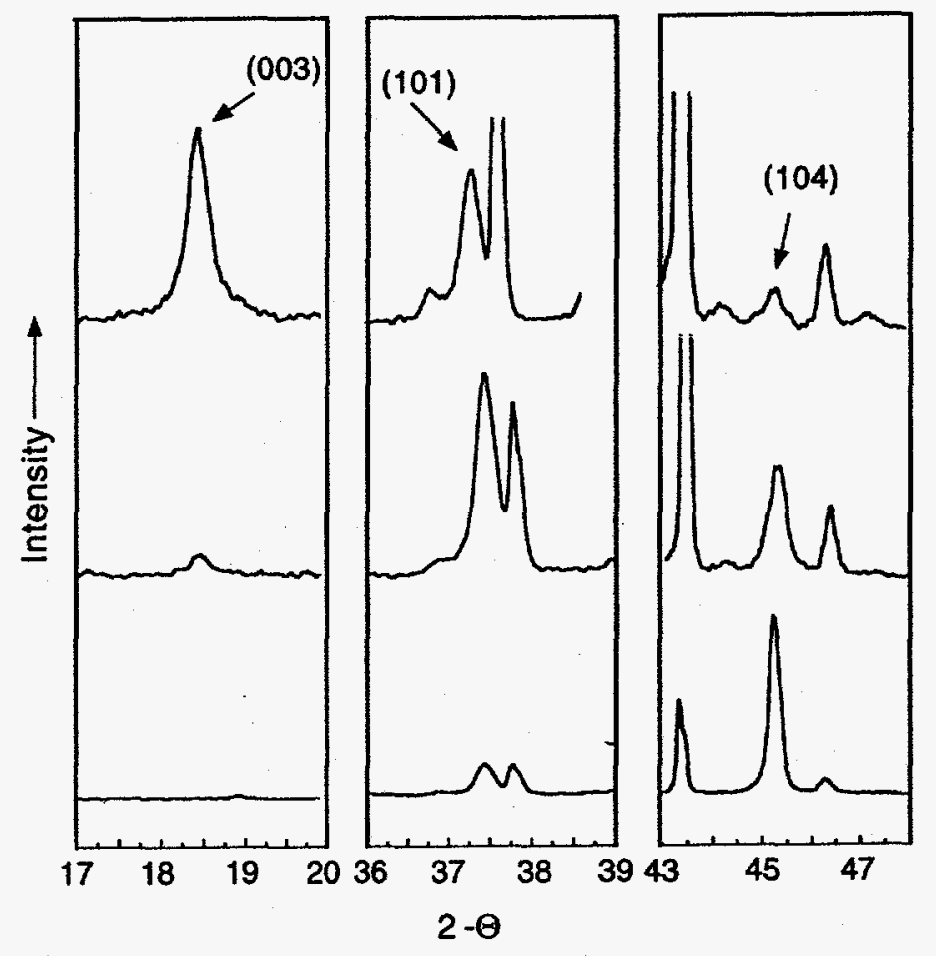




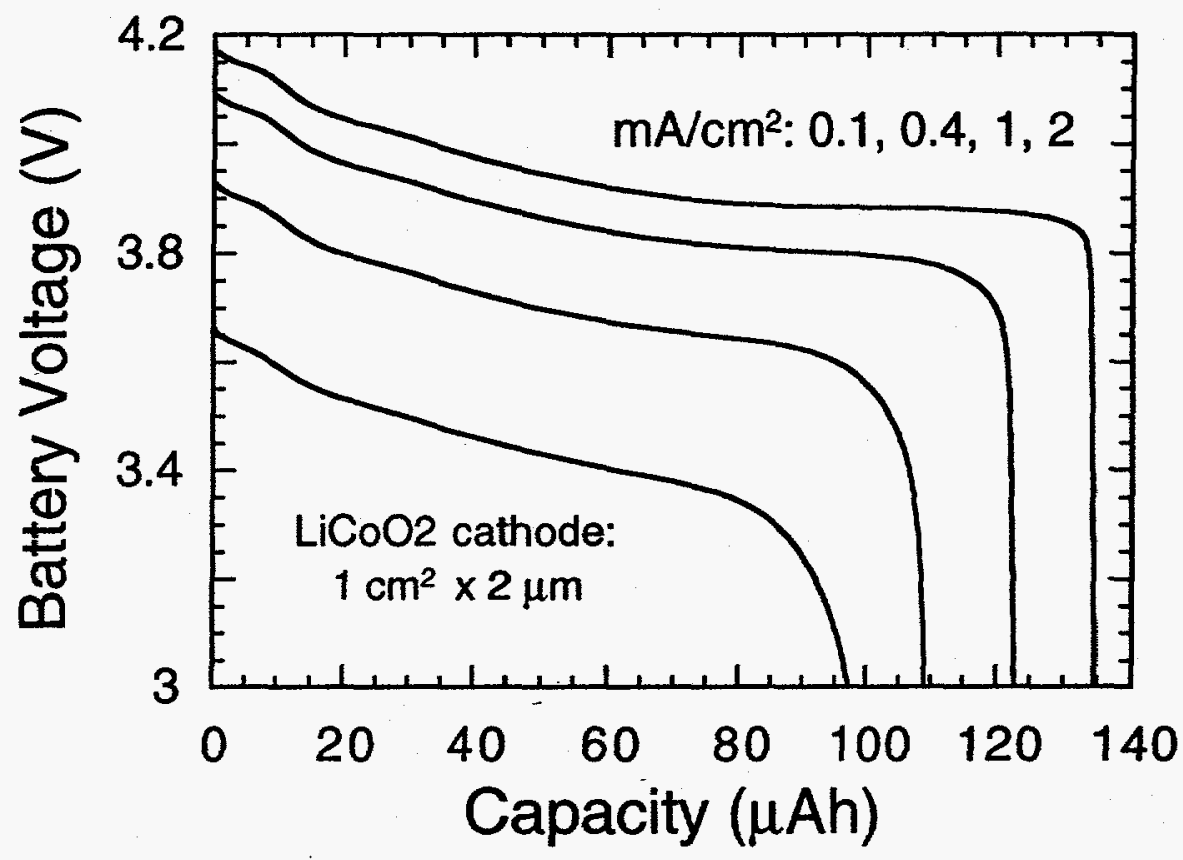




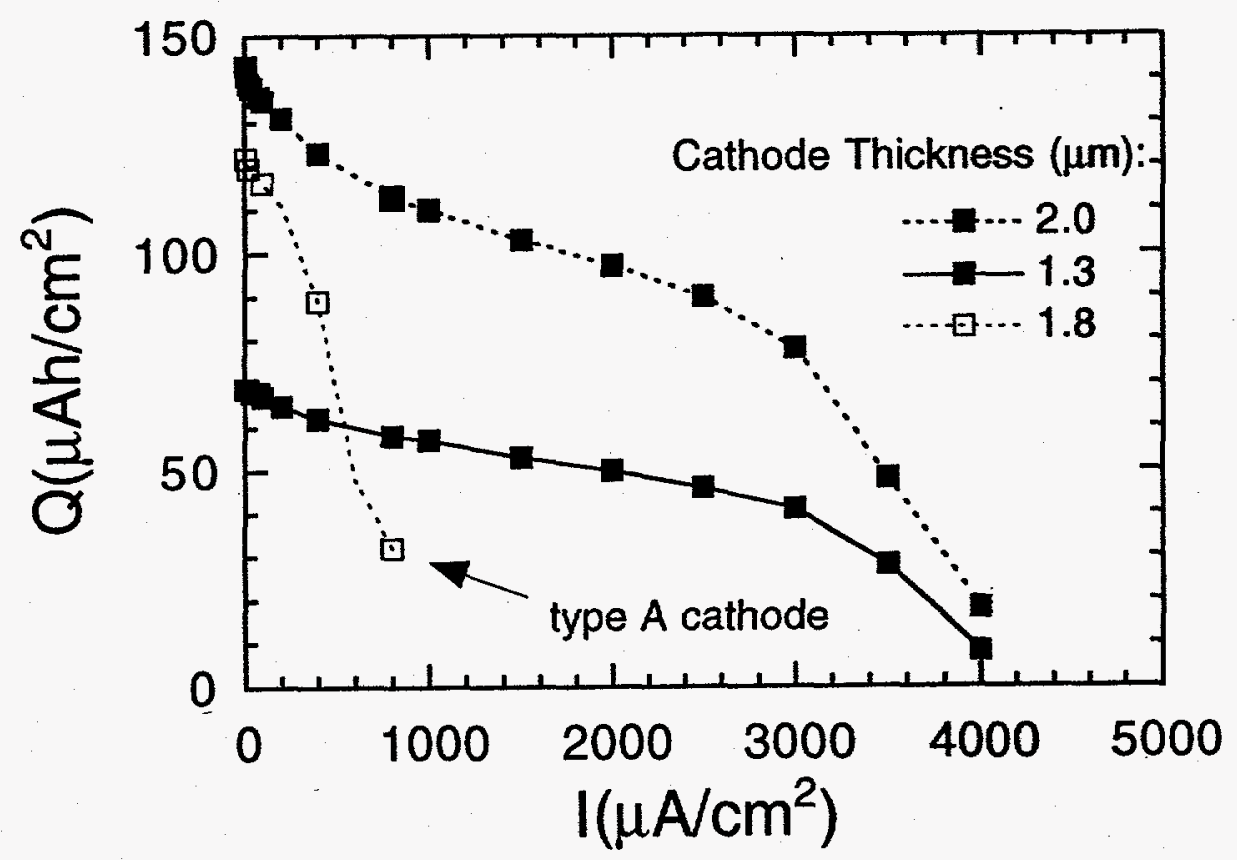




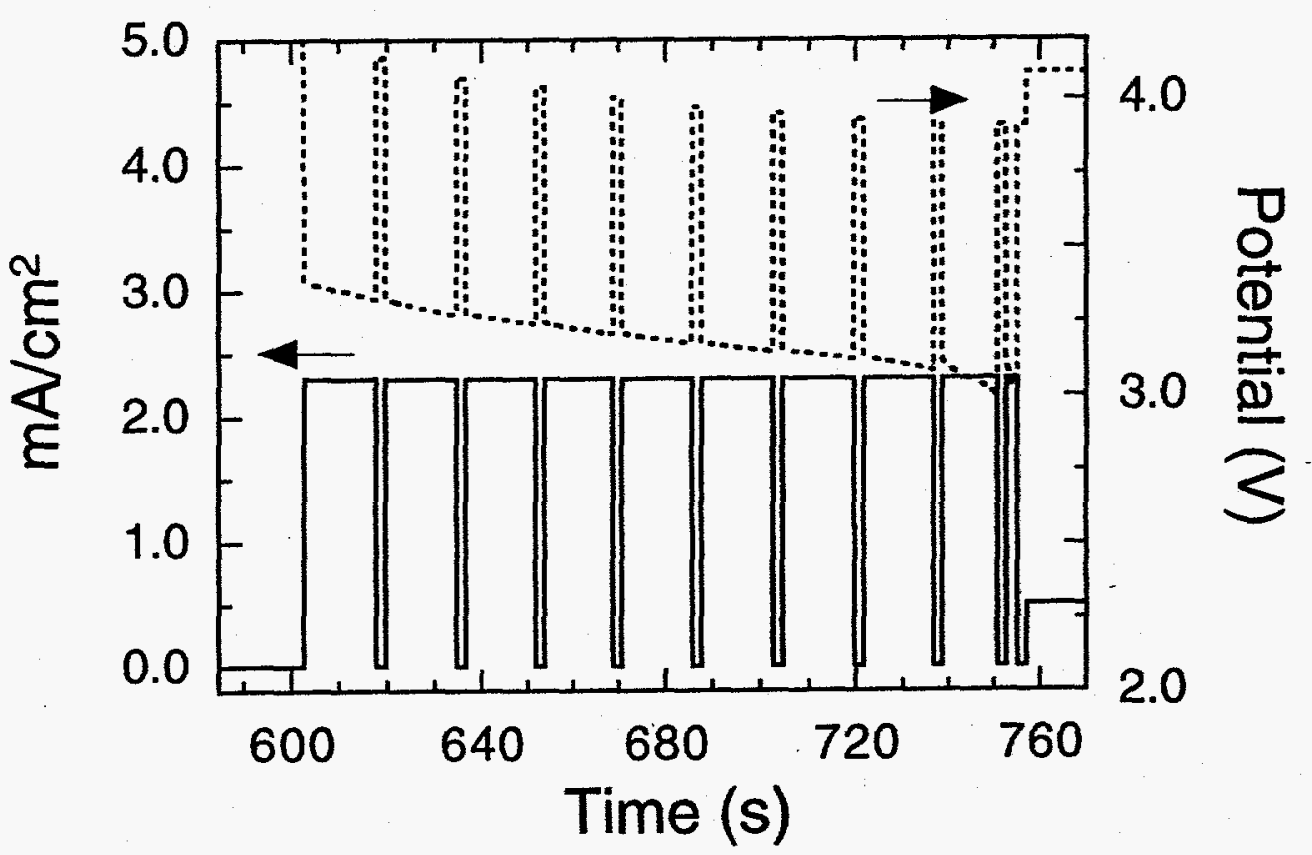




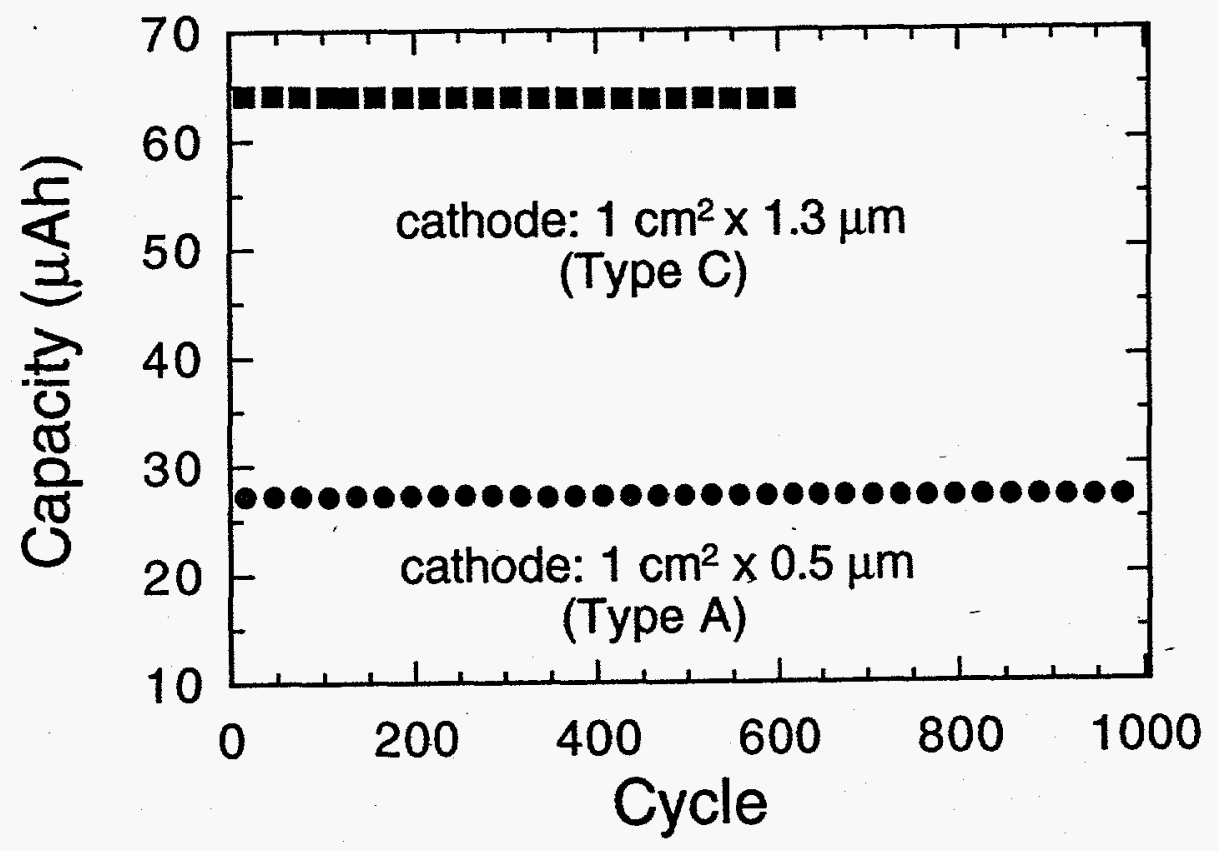

